\title{
Violence against Women in Algeria : Raising Awareness through Teaching Issues of Gender and Masculinities
}

\author{
Amina Babou ${ }^{1}$ \\ ${ }^{1}$ University of Hassiba Benbouali, Chlef, Algeria \\ Coresspondence: Amina Babou,University of Hassiba Benbouali, Chlef, Algeria. \\ Email: aminababou88@yahoo.fr
}

Received: January 2, 2019

Accepted: February 12, 2019

Online Published: March 1, 2019

doi: 10.23918/ijsses.v5i3p159

\begin{abstract}
Gender and violence is a moot and miscellaneous arena which has been proliferated so tremendously and rapidly in recent years. The explosive growth of this field means that each successive decade gets harder to sum up. The scrutiny of violence against women has been a burning issue with regard to the conflicting attempts to define it. In the intended research, we aim at tackling the relationship between violence and gender identities, and to unearth mainly the hidden causes of it. Interestingly, we should note that the violence, we intend to investigate with relation to gender, includes sexual harassment, sexual assault, domestic violence, psychological violence (intimidation and verbal aggressiveness), and forced marriage as well.
\end{abstract}

Keywords: Domesic Violence, Education, Women, Raising Awareness

\section{Introduction}

In any study, it is significant to analyse the role of gender because it takes into consideration the differences between males and females' lives, conversational styles, experiences and opportunities. We live in a society that deprecates women and defines them as inferior to men, where the dominant social construction of masculinity rewards power and may be aggression in particular cases. Basically, we strive to dissect the various aspects of gender-based violence, in the round not just as a static description of this phenomenon, but as a scientific tale of the complex interlocking networks that play a crucial role in violence arousal. As a starting point, we assume that practising violence against women has an intimate relation with negotiating masculinities in different communities of practice in the society. It is imperative to point out that the gist of this research paper is to unveil the points that are at the roots of male violence against women. From this vantage point, we endeavour to embark upon gender-based violence which means any assault directed towards another person (usually female) for one reason or another within male dominated social systems, mainly in the Arab world. This pulls us away to think about the idea which reads that men's violence against women is embedded within a complicated network of patriarchy, andocentric stereotypes and the endeavour to negotiate social/gender masculinities. Moreover, we assume that language may play a momentous role in creating a state of violence and aggression against women. Said differently, male/female conversations typically fall prey to miscommunication and they find it, most of the time, tiresome to fathom the mind of the other. By miscommunication, it is meant to be the mismatch between the speaker's communicative intention and the hearer's understanding of it. 
A plethora of academic evidence is enlisted to bolster the claim that misunderstood signals between males and females may engender job discrimination, rising divorce rates, physical aggression, sexual harassment and rape. Most attempts of this project fells broadly into explaining the intimate relation between cross-sex miscommunication and aggression, either verbal or physical.

\section{Research Methodologies}

As stated earlier, we opt for using the community of practice framework because it plays a pivotal role in cogitating about the pliable nature of an individual's gender identity, since it is blatant that individuals are social actors who are constantly striving to anchor themselves in a wide range of different communities with different norms and values, and they will have; therefore, miscellaneous identity positions within these groups, both dominant and marginal. Since we intend to investigate violence against women as a social practice, we believe that the CofP framework postulates a clear-cut and a penetrating analysis of the intimate relation that exists between language, identity and practice.

Besides drawing on the CofP framework, we tend to trace the critical discourse analysis which is a type of discourse analytical research, which tackles, for the most part, how social power, abuse, dominance and imbalances in power, are enacted, reproduced, and resisted via the use of language (Godeo, 2006). I employ Fairclough $(2001,2003)$ Critical Discourse Analysis (CDA), he defines discourse as 'language as social practice determined by social structures" (2001, p. 14). He (2003) relates CDA to Gramsci's (1971) notion of hegemony. Hegemonic struggle can be related to discourse inasmuch as social structures and discursive practices are constitutive of social structure, in society's norms, conventions, identities and institutions (Fairclough, 2003). He highlights how discourse practice and social cultural practice are useful in the construction of gender identities. Our basic premise is that social power, which is peculiar to men, plays a prominent role in the outburst of male/female miscommunication and may exacerbate the need to practice violence in some cases. Violence is itself a display of power by men against women in a host of cases. Critical discourse analysis researchers are usually more interested in the way discourse re(produces) social dominion and the power misuse of one group over another. Concerning the number of respondents those whom we observed and interviewed, there are 214 embracing both males and females residing in Algeria. They are housewives, educators, professors, with a special focus on the women victims from the National Centre for Girls and Women Victims of Violence and Distress'.

\section{Male Dominance and Social Power Theories}

The dominance theory portrays women as being inferior and weak in comparison with men. Its advocates promulgate the idea that male dominates females by virtue of the former's biological strength, and the latter's physical weakness. Obviously, male dominance theory sustains the state of unequal power to grab the compliance of the less powerful. Men gain, therefore, the lion's share of empowerment according to the dominant approach. In this casting of the male dominance argument, it is still saturated with andocentric stereotypes. By andocentric, is meant the notion that man is the foremost part which dominates and exhibits sovereignty upon women. This concept is attested by the fact that a host of gender stereotypes portray the female sex in a negative manner. Males are, in general, the core power from which females derive their stamina to carry on their lives, as is defined in Dealey and Ward (2009, p. 127) "andocentric is the view that male sex is primary and the female secondary in the organic 
scheme, that all things center, as it were, about necessary in carrying out the scheme, is only the means of continuing the life of the globe, but is otherwise and important accessory and incidental factor in".

We should note that by sex, is meant to be the biological traits of the human being, whether male or female. It has to do with anatomy and physiology. Meanwhile, "Gender" as a term differs from "sex" in being about the socially and psychologically expected characteristics rather than the biological organs provided by nature. If we are to identify male/female social roles and behaviours performed in their daily interactions (particularly in the study of violence perpetuation), we must spring gender differences into considerations. The findings of our analysis of male/female miscommunication and verbal aggressiveness in Algeria tend to endorse Cameron's (2003) line of thought which reads that misunderstanding arises, not because of gender differences, but because of variations in power. Besides, greater social power provides men with the capacity to turn definitions of the situation into physical violence (Cameron, 2003). So, if the trouble really evolved from cultural difference, would we have such solely scenarios?

By way of explanation, Mackinnon (1987) points out that:

"Men's understanding is part of the legal definition of rape. A man must both understand a woman doesn't want intercourse and force her to engage in it anyway, to be conficted of rape" (Quoted in Henley \& Kramarae, 1991, p. 42).

But is rape in such a circumstance actually a matter only of "missed" communication? No, power, in reality, "tracks its dirty feet across this stage" (Henley \& Kramarae, 1991, p. 42). In a similar vein, men tend to employ power in an unconscious manner as a repercussion of gender role prescriptions. Violence against women is tremendously interpreted as motivated by the needs to dominate women.

The Algerian constitution affords the freedom of movement to all citizens. Notwithstanding, Article 39 of the family code stipulates that the duty of the wife is to bear, obey her husband, therefore enduring him even if he is bestial or brutal. She has not the right to complain or return back to her family home after she got married; she has just to succumb to her ruthless and hard-hearted husband. They bear the idea that a divorced woman would be underprivileged and lacking the rights and advantages of the members of society.

Albeit I am not vehemently against taking the permission from the father or the husband to travel or leave home for some reasons, I enormously confute with forbidding wives to consult the doctor merely because women's freedom of movement is confined by social traditions and norms. Unfortunately, 25\% of the respondents report that they were, in many times, exposed to physical aggression at the hands of the husband or the family members for the widow, because they did not take their authorization. For this very reason, they might be severely sanctioned if they try to negotiate their freedom of speech and movement. These women could not even apprehend the meaning of 'women's empowerment'; they are in a sui generis state. They are still wrecking in the swamp of the sightless notions of patriarchy and an andocentricity.

Although the family code reveals that the minimum age for marriage for women is 18 , early marriage of a myriad of girls is prevalent, especially in rural areas in Algeria. To nuance the picture, 29 victims in 
the 'National Centre for Girls and Women Victims of Violence and Distress' in Tipaza (Algeria) have underwent domestic violence and marital rape. The great majority of them were located in peasant provinces.

Articles 336 and 337 which reside in the Algerian penal code reads that punishment for rape is 5 to 10 years in prison and the period will be extended to 20 years if the victim is minor. The room is, therefore, left secure for abusive husbands since state authorities have not directed a limelight on addressing the issues of rape, sexual violence within the family. Besides the tangible repercussion achieved by Algerian women's rights' activists, raising societal awareness around women's rights and issues is of paramount importance, via providing information on the national radio, for instance.

\section{Social Learning of Gender Roles and the Construction of Masculinities}

Social learning theory sustains that humans learn social behaviour by observing others' behaviours and they glean what behaviours are apt to be performed as social agents in the society. They maintain adopting those behaviours that tally with the social norms and gender roles of the society (O'Leary, 1988). This theory does not see aggression as undeniable, but rather views it as a social behaviour that is learned and constructed by its consequence, continuing if it is endorsed. (Lore \& Schultz, 1993). Along this line of thought, Tannen (1990) underpins the idea that women and men belong to two different subcultures. Whilst boys are instructed to cooperate with teammates for the sake of winning, girls learn to cooperate with teammates in order to build and maintain relationships. Lest future social deviation, parents try to transmit the norms to their children and offer them different instructions divulging them what is inimical to their masculinity or to their femininity. Being masculine demands that a man should be intrepid and seeks risky-undertaking adventures even accepting violence if necessary. Male sex role requires that the man should occasionally become a hostile bulwark. Aligning with this idea, calling a man 'aggressive' is usually, in some societies, revered as a compliment.

In some contexts, males tend to negotiate power and construct masculinities via adopting some aggressive behaviour against females. Overall, if we are to cease violence against women and across societies more generally, we need to change the meaning of gender identities and the construction of masculinities. For this very reason, we strive to challenge the notion of gender as a fixed binary opposition, in the scrutiny of gender-based violence, which denies the social agency of both men and women. We try to employ an approach of considerable importance in recent gender studies which is the concept of the 'community of practice' (CofP for short) with a great belief that practice emerges in the course of women's and men's joint activity around common endeavour. To grapple with the full range of issues about gendered identities, we should first painstakingly recognize that the community of practice is "an aggregate of people who come together around mutual engagement in an endeavour" (Eckert and McConnell-Ginet, 1992, p. 464). The concept of the CofP permits a rich, vital and supple tool for the close examination of the relation between male's construction of masculinity and the need to display power against females. Hot criticism has been, therefore, directed to the essentialism ideology which maintains that the construction of gender identity and the social practices within the society are entwined in male dominance and female subordination. Aligning with the essentialist view, violence against women may be seen as a privilege of power which is part of male control. Essentialists claim that gender identity has already been designated by the norms of the community, and, therefore, 
by the folk expectations. We think that this view preserves the idea that yields legitimacy of male dominance and female subordination. This makes us keenly aware that the CofP framework allows for a tremendous breadth of coverage of the salient aspects of gender violence and how women and men come to readjust the meaning of femininity and masculinity, to shape and construct their gender identities; not as a bundle of fixed binary rules but as a tractable practice to negotiate the meaning in order to convey the status quo of the social actors those are interested in playing part of the social negotiation of meaning. Connell (2000) stresses the pivotal role of gender relations and the construction of gender identities for understanding violence, and in particular males' violence. By this token, Connell (2005) perceives hegemonic masculinity as "the cultural dynamic by which a group claims and sustains a leading position in social life" (p.77). This has proved of critical significance as a way to grasp the construction of gender identity and the perpetuation of violence.

If we assume that gender inequalities are pivotal in the perpetuation of violence against women in the Arab world and that these dissimilarities are entrenched in a complex and interlocking network of the normative construction and negotiation of masculinities and femininities, then it is conspicuous that we must engage both women and men, as social agents, in altering the strict binary norms of gender roles and gender identities. In a similar vein, gender based violence cannot be necessarily restricted to women's issue, which can be tackled by negotiating and accentuating women's rights and empowerment. Hooper (2001) suggest that masculinity is, de facto, an empty space with no absolute notions, and that the negotiations over the meanings of masculinity may make feminists cogitate to mutate the meanings and purports of masculine faces.

Aligning with the idea that hegemonic struggles can be related to discourse, our analyses are directed in which power and masculinity can in tandem be achieved, or attempted through Algerian men's discourses. These analyses do not disclose men just as 'perpetuators' of violence but as victims as well. For example, the following extract will exhibit how 'Ali' demonstrates how the normative and hegemonic definitions of masculinity are not constantly achieved by men in the Algerian society in their genuine living experiences.

Ali: Oh...! This is Algeria...we are normally the 'breadwinners', but you know how the state converts the roles. Look! Look! There and see the road. Hmmm.., you find 10 policewomen and 2 policemen! Do you see? How do they say that women are deprecated?

As I hope is blatant by now, problems of unemployment and poverty, for instance, may impede the negotiation of normative masculinities. This hiatus between normative social roles and lived realities of masculinity might be considered as one of the causative factors in the performance of gender-based violence. Along this line of thought, Connell states that "violence is part of a system of domination, but is at the same time a measure of imperfection" (1995, p. 85).

The following extract of 'Larbi' may elucidate the fact that some Algerian men feel a fiasco to live up with the ideal constructions of dominant masculinities as rewarded by the social norms and the religious beliefs of the society.

'Larbi' says about his wife: 
Ah... Is it necessary to narrate what happened last week? Hmmm....aggression (pause). They know only aggression and abuse. Haa... She is always the victim and I am always the perpetuator. She... (pause). She wants to become the gatekeeper.

Ah yes... She thinks that she can delete my masculinity by her monthly pay! I am the man and she is the woman. I.... will break her head if she will boast like that and reprove me that way... in front of my son.

Imbalances at the societal level are nourished within the family when men exercise power and control over women and create, as a consequence, one form of which is violence. Feminists reveal that domestic violence cannot be studied without prior recognition and understanding of the society as being structured along the lines of gender, with men as a class possessing sway and power over women: a patriarchal structure. On the basis of the examination we have embarked upon, western models of gender feminism cannot be applied to the Arabic socio-cultural context without prior understanding of the workings of the latter.

\section{The Relation between Male/Female Miscommunication and Violence}

It is an insight worth attending to even now, conversations between men and women often derailed by the lack of agreement on the meaning, and this may open up room for some kinds of verbal aggressiveness or physical violence. The prevalent popular stereotypes, mainly in the Arab world, have been for a long time delineating men as aggressive agents and women as passive listeners and as coopted quoting the social norms expected by the speech community. As a matter of fact, the pendulum has swung to women's agency, in some cases, which is demonstrated in a number of conversational strategies that they adopt for the sake of self expression and self assertion. In our examination of male/female miscommunication in Algeria, the findings reveal how women are perceived to interrupt, challenge and control the floor as much as men if not more. Unfortunately, male/female miscommunication can turn into not only verbal aggression, but also to females' battering and physical abuse. For this reason we think that the study of miscommunication is salient in exploring the research avenue of violence against women.

As for the conversational differences between Algerian males and females, the meaning of minimal responses, such as, mmm, ih (yes in English) is a fairly moot point that may engender male/female miscommunication and verbal or physical aggression as reported by the great majority of our respondents. Whilst men interpret the use of minimal responses as a message to eschew from the conversation and a signal of phlegm and insouciance, the overwhelming majority of our female respondents tend to perceive them as a kind of supportive speech which does encourage the speaker. For this very reason, men are customarily irritated by females' use of minimal responses since they tend to restrict their expectations to only what they think and not what the other speaker really intends to mean.

The findings demonstrate that the meaning of such responses denote neither "Continue, I'm listening", nor "I agree, I follow you" which is assumed to be men's interpretation. Male respondents blatantly agree to perceive the use of minimal responses as a ploy to tell other interlocutors that they cannot go ahead in holding the conversation or they intend to send the message "Speak, but I am not listening" to the other speakers. As expected, the overwhelming majority of our male respondents tend to use minimal 
responses as a kind of a hoot or contempt, whilst some men tend to use those responses to convey their reluctance to duck or evade from the conversation.

What we can reap from these points is that in many different-sex groups, females' use of minimal responses seems to vex male speakers because their understanding of the use of responses stemmed from the general rule among men that reads that the sense of "mm", "hmm" tends to belittle what the other interlocutor is saying.

\section{Conclusion}

To précis the point over again, the bottom line of the current study is to reach plausible and exhaustive explanation to the burning issue of violence against women, allowing space for the bustling concourse of voices and findings in this arena of research.

Besides, we intend to leave room for the analysis of the manner the mothers-in-law, in the Arab world and particularly in Algeria, negotiate and construct their gender identities as blended with an exercise of power and control over their daughters-in-law. It is crucial to point out that the role of the mother-in-law is perhaps the solely, or at least one of the very few positions in which women actively practice predominance, hegemony and power. What is of particular interest here is to what extent the folk expectations differ in judging males' violence and females' violence against other women. By analogy to other cultures, the Algerian culture negatively perceives this case of females' power and domination, even over other women. And this is perhaps glaringly different from the perception of men's power and sovereignty.

All in all, if we are to stop violence against women, especially in the Arab world, we need to have a generic understanding of the main reasons behind the practice of violence against women, whether the reasons are psychological, linguistic, or by virtue of social power afforded by the society. The relation between gender and violence is complex and it is of paramount importance to scrutinize gender- based violence. Differences in gender norms and roles often create inequalities, whereby one gender (usually males) becomes empowered to the disadvantage of the other. For this very reason, teaching gender norms and how to change the construction of masculinities are required.

Studies on gender-based violence have often focused on women's issues and attempt to grapple with the full range of issues of the construction of femininities to examine how violence takes place. Not to touch the tip of an iceberg in this arena of research, I tremendously boost the in-depth understanding and the consideration of how the constructions of masculinities are constantly negotiated so as to resist what may jeopardize their status-quo.

\section{References}

Cameron, D. (2003). Gender and Language Ideologies. In J. Holmes and M. Myerhoff, eds, The handbook of language and gender. Oxford: Blackwall, pp. 447-67.

Connell, R. W. (2000). The men and the boys. Cambridge: Polity Press.

Connell, R. W., \& Messerschmidt, J. (2005). Hegemonic masculinity: Rethinking the concept. Gender and Society 19(6), 829-859.

Dealey, J. Q., \& Ward, F. (2009). A text-book of sociology. New York. 
Eckert, P., \& McConnell-Ginet, S. (1992). Think practically and look locally: Language and gender as community-based practice. Annual Review of Anthropology, 21, 416-90.

Fairclough, N. (2001a). Critical discourse analysis as a method in social scientific research, in R. Wodak \& M. Meyer (eds.), Methods of critical discourse analysis. London,UK: Sage Publications.

Fairclough, N. (2003). 'Political correctness': The politics of culture and language. Discourse and Society, 14(1), 17-28.

Godeo, G. (2003). Critical discourse analysis and the identification of homosexism in discourse: A case study. In Martinez, P. I. P Fifty years of english studies in spain (1952-2002). A commemorative. Santiago de Compostela: University of Santiago.

Gramsci, A. (1971). Selections from the Prison Notebooks. Translated and edited by Quintin Hoare and Geoffrey Nowell Smith. New York: International Publishers.

Henley, N., \& Kramarae, C. (1991). Gender, Power and Miscommunication In N. Coupland, H. Giles, and J. Wiemann. (eds) Miscommunication and problematic talk. Newbury Park, CA: Sage.

Lore, R. K., \& Schultz, L. A. (1993). Control of human aggression : A comparative perspective. American Psychologist, 48, 16-25.

O'Leary, K. (1988). Physical aggression between spouses: A social learning theory perspective. In R. Van. Hasselt, R. Morrison, A. Bellack, \& M. Hersen (Eds.), Handbook of family violence (pp.31-55). New York: Plenum Press.

Tannen, D. (1990). You just don't understand: Women and men in conversation. London: Virago. 